\title{
Structural and Functional Arterial Parameters, Immunovirological Control and Vitamin D in HIV-Infected Patients
}

Alexandra Yannoutsos ${ }^{1}$, Davide Agnoletti ${ }^{1}$, Julie Peroz-Froz ${ }^{1}$, Camille Ly, Helene Lelong ${ }^{1}$, Jirar Topouchian ${ }^{1}$, Jacques Gilquin ${ }^{2}$, Segolene Boucly ${ }^{2}$, Hafeda Rostane $^{2}$, Michel E Safar ${ }^{1}$, Jean-Paul Viard ${ }^{2,3^{*}}$ and Jacques Blacher ${ }^{1}$

${ }^{1}$ Paris Descartes University, Faculty of Medicine; AP-HP; Diagnosis and Therapeutics Centre, Hypertension and Cardiovascular Prevention Unit, Hôtel-Dieu Hospital, Paris, France

${ }^{2}$ Paris Descartes University, Faculty of Medicine; AP-HP; Diagnosis and Therapeutics Centre, Immunology and Infectiology Unit, Hôtel-Dieu Hospital, Paris, France ${ }^{3}$ Paris Descartes University, EA 7327, France

"Corresponding author: Jean-Paul Viard, Paris Descartes University, Faculty of Medicine; AP-HP; Diagnosis and Therapeutics Centre, Immunology and Infectiology Unit, Hôtel-Dieu Hospital, 1 Place du Parvis Notre-Dame 75181 PARIS Cedex 04, France. Tel: 0033 (0)1 42348836 ; Fax: 0033 (0)1 42348852 ; E-mail: jeanpaul.viard@htd.aphp.fr

Received date: July 25, 2014; Accepted date: November 19, 2014; Published date: November 25, 2014

Copyright: (c) 2014 Yannoutsos A, et al. This is an open-access article distributed under the terms of the Creative Commons Attribution License, which permits unrestricted use, distribution, and reproduction in any medium, provided the original author and source are credited.

\section{Abstract}

Objective: HIV-infected patients still experience higher Cardiovascular (CV) mortality rates, even if an adequate viral suppression is achieved. In addition, vitamin D insufficiency, a common condition in HIV-infected patients, is increasingly associated with $\mathrm{CV}$ risk. We therefore aim to investigate relationships between immunological parameters, antiretroviral therapy, plasma vitamin D and arterial parameters, including aortic stiffness and wave reflections, in HIV-infected patients who achieved viral suppression but possibly remain at increased CV risk.

Methods: We conducted a cross-sectional study including 178 middle-aged HIV-infected patients. HIV infection was controlled in a large number of participants, representative of a real-world setting. In addition to carotid Intima Media Thickness (IMT), central hemodynamic parameters involved aortic Pulse Wave Velocity (PWV), carotid Augmentation index (Alx) and Pulse Pressure Amplification (PPA) measured noninvasively using applanation tonometry.

Results: Aortic PWV was slightly but unsignificantly higher than the theoretical values obtained in general population according to age and blood pressure, and was independent of HIV-related parameters. In univariate and multivariate analyses, carotid Alx was positively correlated with current CD4 T-cell count and PPA was positively correlated with vitamin $D$, independently of other confounders. No HIV-related parameters or vitamin D entered the multivariate analysis of carotid IMT / plaque.

Conclusion: In our chronically treated population, HIV infection was not associated with increased aortic stiffness but with a positive correlation between current CD4 T-cell count and degree of Alx, suggesting that patients with higher CD4 T-cell count may have higher wave reflections. The positive correlation between vitamin D and PPA suggests that vitamin $D$ deficiency may be independently associated with altered central hemodynamics in well controlled HIV-infected patients. These findings should be confirmed in prospective studies.

Keywords: HIV infection; Aortic stiffness; Pulse wave velocity; Arterial wave reflections; Pulse pressure amplification; Cardiovascular disease risk factors; Plasma vitamin D

\section{Introduction}

Combined antiretroviral therapy has led to a substantial decline in AIDS-related morbidity and mortality [1,2]. Mortality and overall incidence of opportunistic infections declined markedly in 1996 and early 1997 with the introduction of combination therapy including protease inhibitor (PI) [1]. In the mid-2000s, despite a near-normal life expectancy, HIV-infected patients presented excess mortality rates compared to the general population; the estimated median remaining lifetime of a 25-year-old HIV-infected individual was 39 years compared to 51 years for a 25-year-old HIV-uninfected person [3]. Patterns of co-morbidities and causes of death have changed. More specifically, cardiovascular (CV) diseases became one of the leading causes of death in this population [2]. The French national survey, describing the causes of death among HIV-infected patients in France in 2010 and their evolution since 2000, has highlighted an increase in the proportion of $\mathrm{CV}$ deaths in middle-aged patients, between 40 and 59 years [4]. HIV replication and incomplete immune restoration or persistent immune activation (as reflected by a high CD8 cell count or a $\mathrm{CD} 4 / \mathrm{CD} 8$ ratio $<1$ ) were independently related to the risk of myocardial infarction [5]. High burden of traditional risk factors and cumulative exposure to Highly Active Antiretroviral Therapy (HAART), especially to PI, may also account for increased CV risk $[5,6]$.

Recently, evidence from large prospective cohort studies has highlighted that HIV-infected patients with viral suppression and who maintained or had recovered CD4 T-cell counts of at least 500 cells $/ \mathrm{mm}^{3}$ in the HAART era, had no evidence for a raised risk of death compared with the general population [7]. In contrast, patients with CD4 T-cell counts less than 500 cells $/ \mathrm{mm}^{3}$ still experienced 
Citation: Yannoutsos A, Agnoletti D, Peroz-Froz J, Camille Ly, Lelong H, et al. (2014) Structural and Functional Arterial Parameters, Immunovirological Control and Vitamin D in HIV-Infected Patients. J AIDS Clin Res 5: 375. doi:10.4172/2155-6113.1000375

Page 2 of 9

higher mortality rates, even if viral suppression was achieved [7]. The commonest causes of death were CV disease and sudden death, highlighting the need for improved CV risk prediction and prevention in this population [7].

Routine CV risk prediction in HIV-infected patients is estimated with conventional risk prediction models but these tools do not include HIV-specific markers. Furthermore, because of their inability to integrate individual levels of intensity and exposure to all CV risk factors, such models of risk stratification may underestimate CV risk in young and middle-aged HIV-infected patients or those with the metabolic syndrome [8]. Nevertheless, several previous studies have highlighted greater structural and functional arterial damage in HIVinfected patients compared to uninfected individuals [9,10]. Rather than increased carotid intima-media thickness (IMT) [11,12], carotid to femoral pulse wave velocity (PWV), a measure of aortic stiffness, has allowed to gather the largest amount of evidence regarding added predictive value for $\mathrm{CV}$ risk, over and above traditional risk factors, and persisting even after adjustment for carotid IMT and carotid stiffness [13-15]. Central augmentation index (AIx), which is considered a transit time-dependent marker of intensity of arterial wave reflections, and pulse pressure (PP) amplification, also bring independent predictive value for $\mathrm{CV}$ events and mortality $[16,17]$. However, such parameters may be difficult to interpret in HIVinfected patients because the association between HIV infection and greater arterial stiffness or wave reflections may be no longer significant after adjustment for classical risk factors, especially smoking and hypertension [18].

Little and inconsistent evidence exists about the relationship between virological and immunological parameters and arterial stiffness and wave reflections in HIV-infected patients [19-21]. Our aim was to investigate the relationships between immune status and arterial parameters, including aortic stiffness and wave reflections, in middle-aged HIV-infected patients who achieved viral suppression but possibly remain at increased CV risk.

In addition, vitamin D insufficiency is a common condition [22] and has been associated with CV morbidity [23] and increased allcause and CV mortality in the general and HIV-infected populations $[24,25]$. In order to better assess CV damage and its determinants in HIV-infected patients, we therefore investigated cross-sectional correlations between structural and functional arterial parameters, HIV-related factors and vitamin D status.

\section{Methods}

\section{Study population}

Among HIV-infected persons routinely followed up for immunovirological, CV, metabolic, and bone health parameters at the Paris Hôtel-Dieu hospital, 178 consecutive HIV-1-infected patients in primary CV prevention, 143 men and 35 women, were included in this cross-sectional study, between September 2010 and July 2011. Exclusion criteria were age under 18, acute medical conditions and atrial fibrillation. No patient had any active AIDS-related condition at inclusion in the study. No patient had a past or present history of endocarditis and no patient had any active bacterial infection at the time of study. No active intravenous drug user was included in the study. Patients provided informed consent for additional hemodynamic measurements and data collection. The study was approved by our institutional review board.

\section{Clinical and laboratory parameters}

We recorded data on HIV clinical classification, comorbidities, CV risk factors, current medications including statin and antihypertensive therapy, past and present ART regimens, duration of ART and nadir CD4 T-cell count. Laboratory parameters, including plasma glucose and $\mathrm{HbA1C}$, cholesterol (total, LDL and HDL) and triglycerides, renal function, 25-hydroxyvitamin D (25OHD), CD4 and CD8 T-cell counts, and viral load (HIV RNA copies/ml) were determined on the day of hemodynamic measurements.

The metabolic syndrome was defined by the presence of at least three out of the five following criteria according to the Third Report of the National Cholesterol Education Program: 1) SBP above 130 $\mathrm{mmHg}$ and/or DBP above $85 \mathrm{mmHg}$, or treated hypertension, 2) waist circumference over $102 \mathrm{~cm}$ in men and $88 \mathrm{~cm}$ in women, 3) triglyceride concentration above $1.69 \mathrm{mmol} / \mathrm{l}, 4) \mathrm{HDL}$-cholesterol concentration below $1.04 \mathrm{mmol} / \mathrm{l}$ in men and $1.29 \mathrm{mmol} / \mathrm{l}$ in women, and 5) fasting plasma glucose concentration above $6.1 \mathrm{mmol} / \mathrm{l}$.

\section{Central and peripheral arterial parameters}

Hemodynamic measurements were performed in the morning after an overnight fast, in supine position. Peripheral Systolic BP (SBP) and diastolic $\mathrm{BP}(\mathrm{DBP})$ were measured at both arms using an automatic BP monitor (OMRON 705 CP II IT) after 5 minutes of rest. Five measurements 2 minutes apart were averaged. Heart rate was recorded.

After BP determination, structural and functional parameters of the arterial wall were performed noninvasively by applanation tonometry: this measure provides an accurate profile of intra-arterial BP curves, with a continuous beat-to-beat monitoring, by applying a piezoelectric sensor, the tonometer, over an artery. The reproducibility of these measurements, in our group and in others, has been previously published in detail $[26,27]$.

Carotid-femoral PWV is considered as the gold standard direct and non invasive test for aortic stiffness assessment [28]. The aortic PWV measurement was performed using an automatic device, the SphygmoCor, which allowed on-line pulse wave recording and automatic calculation of PWV. Aortic PWV was calculated as the distance between carotid and femoral arteries, divided by the time interval between the feet of the pressure waves at the recording sites. Pulse waveforms were obtained transcutaneously using applanation tonometry over the common carotid and femoral arteries. The carotidfemoral pathway was the direct distance measured using a standard compass system between the carotid and femoral measurement sites. Direct distance was multiplied by a scaling factor of 0.8 to obtained "real PWV" as previously described [29]. Transit time was assessed as the time difference between two characteristic points ('foot of the wave') on carotid and femoral waveforms at the measurement sites.

Central BP components (SBP, DBP and PP), were estimated by the pulse wave analysis of the common carotid artery. Pulse pressure amplification was defined as the brachial PP-to-carotid PP (B/C) ratio. Amplification of systolic and pulse pressures from central to peripheral sites depends on the timing and amplitude of the reflected waves. Normal values of PPA vary from 1.7 at less than 20 years of age to 1.2 at more than 80 years of age [16].

Augmentation index is estimated from the pulse waveform measured directly at the carotid artery. This index is defined as the pressure augmentation (which is the difference between the second 
Citation: Yannoutsos A, Agnoletti D, Peroz-Froz J, Camille Ly, Lelong H, et al. (2014) Structural and Functional Arterial Parameters, Immunovirological Control and Vitamin D in HIV-Infected Patients. J AIDS Clin Res 5: 375. doi:10.4172/2155-6113.1000375

Page 3 of 9

and first systolic peaks) expressed as a percentage of PP. AIx is frequently used to assess wave reflection, and is affected by both timing and amplitude of the reflected waves. Carotid and aortic AIx are known to be strongly and positively correlated [30]. There is a non-linear relationship between normal vascular ageing and enhanced AIx, more marked in individuals under 50 [31]: in out-of-hospital community-based population considered to represent the normal population, AIx values vary from $1.6 \%$ at less than 10 years of age to $24.1 \%$ at more than 60 years of age [32].

Carotid IMT was determined ultrasonographically, in supine position, using Sigma 110 KONTRON and a 7.5-13 MHz linear array probe. Carotid arteries, abdominal aorta and limb arteries were scanned ultrasonographically for the detection of plaques and stenosis. Echocardiography was performed for left ventricular systolic and diastolic function study.

\section{Statistical analysis}

Statistics were performed with SAS software version 9.0 (SAS Institute, Cary, NC). A $\mathrm{p} \leq 0.05$ was considered as statistically significant. We represented quantitative variables as mean \pm standard deviation $( \pm \mathrm{SD})$, or median (interquartile range, IQR) for non-normal variables. Qualitative variables are expressed as frequency and percentage.

Theoretical aortic PWV values in our study population were calculated by age category on the basis of Mean Arterial Pressure (MAP) according to The Reference Values for Arterial Stiffness' Collaboration study [29]. Mattace-Raso et al. provided normal and reference values for aortic PWV based on a large European population of 11092 non diabetic subjects without overt CV disease and without current treatment for hypertension or for dyslipidemia. The reference value population included subjects with a mean age of 50 years, with high normal or high BP, with dyslipidemia and/or smoking [29]. To test whether aortic PWV measured values in our study population are different from calculated theoretical values, we used the MannWhitney U test.

For regression analysis non-normal variables were log transformed. Multiple regression analyses were performed on PWV, AIx, PPA, and IMT; logistic regression was done for the presence of carotid plaques. Regressions models were obtained by stepwise selection, containing all variables that were significantly correlated in univariate analysis and based on their physiopathological plausibility. Variables that entered the stepwise selection were age, MAP, heart rate, gender, diabetes, smoking status, waist circumference, plasma 25OHD level, PI treatment, nadir CD4 T-cell count and current CD4 T-cell count. For hemodynamic parameters, age and MAP were forced into the models. For AIx and PPA, heart rate and gender were also forced into the multivariate models [33-34].

\section{Results}

\section{Clinical, biological and HIV-related parameters}

Characteristics of the study population are summarized in Table 1. Patients were mostly men (80\%), with a mean ( \pm SD) age of $49 \pm 9$ years, and $49 \%$ were smokers (only $13 \%$ current smokers). More than a half $(52 \%)$ presented with the metabolic syndrome. $5 \%$ of patients were diabetic, $22 \%$ were on antihypertensive therapy and $20 \%$ on a statin. Median (IQR) value for plasma $25(\mathrm{OH})$ D level was 24 (15-34) $\mathrm{ng} / \mathrm{ml} .18 \%$ of patients had a history of AIDS-defining events and $76 \%$ were treated with PIs. $90 \%$ of patients had a viral load below 50 copies $/ \mathrm{ml}$ and only $6 \%$ had a viral load of 400 copies $/ \mathrm{ml}$ or more, which led to a very skewed distribution. Thus, we could not incorporate this variable in the statistical analysis. CD4 T-cell count was $\geq 500 / \mathrm{mm}^{3}$, between $200-500 / \mathrm{mm}^{3}$ and $<200 / \mathrm{mm}^{3}$ in $55 \%, 39 \%$ and $6 \%$ of patients, respectively.

\begin{tabular}{|c|c|c|c|c|}
\hline Variables & $\mathbf{N}$ & Mean \pm SD & Minimum & Maximum \\
\hline \multicolumn{5}{|c|}{ Clinical and biological parameters } \\
\hline Age, years & 178 & $49 \pm 9$ & 21 & 79 \\
\hline Male gender, $\mathrm{n}(\%)$ & 178 & $143(80)$ & & \\
\hline${ }^{\mathrm{a} B M I}, \mathrm{~kg} / \mathrm{m}^{2}$ & 178 & $25 \pm 4$ & 16 & 42 \\
\hline Waist circumference, $\mathrm{cm}$ & 178 & $91 \pm 11$ & 64 & 131 \\
\hline Metabolic syndrome, $n(\%)$ & 148 & $77(52)$ & & \\
\hline Current smokers, $\mathrm{n}(\%)$ & 162 & $21(13)$ & & \\
\hline Former smokers, $\mathrm{n}(\%)$ & 162 & $59(36)$ & & \\
\hline $\begin{array}{l}\text { Anthihypertensive therapy, } \\
\mathrm{n}(\%)\end{array}$ & 176 & $39(22)$ & & \\
\hline Statin therapy, n (\%) & 175 & $35(20)$ & & \\
\hline Diabetics, n (\%) & 178 & $9(5)$ & & \\
\hline Total cholesterol, mmol/L & 145 & $5.33 \pm 1.01$ & 2.85 & 8.55 \\
\hline bHDL cholesterol, mmol/L & 145 & $1.26 \pm 0.44$ & 0.50 & 4.40 \\
\hline $\begin{array}{l}\text { 25-hydroxyvitamin } \quad D^{*}, \\
\mathrm{ng} / \mathrm{mL}\end{array}$ & 153 & $24(15-34)$ & 5 & 68 \\
\hline \multicolumn{5}{|l|}{ HIV-related parameters } \\
\hline $\begin{array}{l}\text { cDuration of PI treatment, } \\
\text { months }{ }^{*}\end{array}$ & 120 & $84(44-171)$ & 0 & 361 \\
\hline $\begin{array}{l}\text { Number of patients treated } \\
\text { with } \mathrm{PI}, \mathrm{n}(\%)\end{array}$ & 157 & $120(76)$ & & \\
\hline Nadir CD4 coun $^{\mathrm{n}^{*}}$ & 169 & $236(90-325)$ & 0 & 889 \\
\hline Current CD4 count $^{*}$ & 174 & $\begin{array}{l}560 \\
(402-740)\end{array}$ & 49 & 2174 \\
\hline Current CD8 count ${ }^{*}$ & 172 & $\begin{array}{l}692 \\
(549-914)\end{array}$ & 75 & 2101 \\
\hline $\mathrm{CD} 4 / \mathrm{CD} 8$ & 131 & $0.88 \pm 0.43$ & 0.06 & 2.78 \\
\hline Nadir CD4 / current CD8* & 167 & $\begin{array}{l}0.339 \\
(0.107-0.553)\end{array}$ & 0 & .55 \\
\hline $\begin{array}{l}\text { HIV classification: } \mathrm{A} \text { or } \mathrm{B}, \\
\mathrm{n}(\%)\end{array}$ & 141 & $116(82)$ & & \\
\hline HIV classification: $\mathrm{C}, \mathrm{n}(\%)$ & 141 & $25(18)$ & & \\
\hline \multicolumn{5}{|c|}{$\begin{array}{l}\text { Continuous variable are presented as mean } \pm \text { standard deviation (SD); discrete } \\
\text { variables as number (percent) }\end{array}$} \\
\hline \multicolumn{5}{|c|}{ FFor skewness distribution, median (interquartile range) is presented; } \\
\hline \multicolumn{5}{|c|}{ 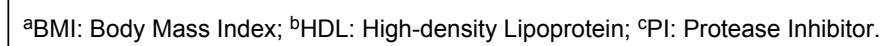 } \\
\hline
\end{tabular}

Table 1: Clinical, biological and HIV-related parameters. 
Citation: Yannoutsos A, Agnoletti D, Peroz-Froz J, Camille Ly, Lelong H, et al. (2014) Structural and Functional Arterial Parameters, Immunovirological Control and Vitamin D in HIV-Infected Patients. J AIDS Clin Res 5: 375. doi:10.4172/2155-6113.1000375

Page 4 of 9

\section{Central and peripheral arterial parameters}

Arterial parameters of the study population are summarized in Table 2. Concerning peripheral hemodynamic parameters, median values (IQR) for brachial SBP, DBP, PP and MAP were 125.5(118-135) $\mathrm{mmHg}, 81(74-88) \mathrm{mmHg}, 45.5(40-50) \mathrm{mmHg}$ and $95(88-103) \mathrm{mmHg}$, respectively. Concerning central hemodynamic parameters, median values (IQR) for carotid SBP, DBP and PP were 113(105-124) $\mathrm{mmHg}$, 81(75-88) $\mathrm{mmHg}$ and 33(28-38) $\mathrm{mmHg}$, respectively. Median value (IQR) for carotid-femoral PWV in our study population was 8.3(7.5-9.5) $\mathrm{m} / \mathrm{sec}$, which was slightly higher than the theoretical carotid-femoral PWV calculated by age category on the basis of MAP [median (IQR): 8.0(7.4-9.1) m/sec]. However, the difference between measured and calculated theoretical aortic PWV did not reach significance (Mann-Whitney $\mathrm{U}$ test, $\mathrm{p}=0.09)$. The mean value $( \pm \mathrm{SD})$ for carotid AIx and PPA were $1.0 \pm 18.6 \%$ and $1.38 \pm 0.20 \%$, respectively. Concerning ultrasonographic measurement, the mean value $( \pm$ SD) for carotid IMT was $0.738 \pm 0.152 \mathrm{~mm}$ and $11 \%$ of patients had at least one carotid plaque.

\begin{tabular}{|c|c|c|c|c|}
\hline Variables & $\mathbf{N}$ & Mean \pm SD & Minimum & Maximum \\
\hline Brachial SBP*a, mmHg & 174 & $125.5(118-135)$ & 95 & 198 \\
\hline Brachial DBP*b, mmHg & 174 & $81(74-88)$ & 61 & 121 \\
\hline Brachial $\mathrm{PP}^{*} \mathrm{c}, \mathrm{mmHg}$ & 174 & $45.5(40-50)$ & 25 & 91 \\
\hline Heart rate, bpm & 177 & $69 \pm 12$ & 42 & 107 \\
\hline $\mathrm{MAP}^{* \mathrm{~d}}, \mathrm{mmHg}$ & 161 & $95(88-103)$ & 73 & 146 \\
\hline Carotid SBP*, mmHg & 161 & $113(105-124)$ & 89 & 205 \\
\hline Carotid DBP*, mmHg & 161 & $81(75-88)$ & 61 & 120 \\
\hline Carotid PP*, mmHg & 161 & $33(28-38)$ & 21 & 97 \\
\hline cf-PWV*et, m/s & 173 & $8.3(7.5-9.5)$ & 5.8 & 16.9 \\
\hline Theoretical PWV ${ }^{\star} \neq, \mathrm{m} / \mathrm{s}$ & 174 & $8.0(7.4-9.1)$ & 5.6 & 13.5 \\
\hline Carotid Alx', \% & 161 & $1.0 \pm 18.6$ & -50.0 & 42.6 \\
\hline $\begin{array}{l}\text { Pulse pressure } \\
\text { amplification, } \%\end{array}$ & 156 & $1.38 \pm 0.20$ & 1.02 & 1.96 \\
\hline Carotid plaque, n (\%) & 158 & $18(11)$ & & \\
\hline $\mathrm{IMT}^{\mathrm{g}}, \mathrm{mcm}$ & 173 & $738 \pm 152$ & 460 & 1405 \\
\hline
\end{tabular}

Continuous variable are presented as mean \pm standard deviation (SD); discrete variables as number (percent);

*For skewness distribution, median (interquartile range) is presented;

${ }^{\dagger}$ Calculated as direct distance divided by transit time multiplied by 0.8 ;

$\mp$ Calculated by age category on the basis of mean blood pressure; test for difference between cf-PWV and Calculated Theoretical PWV: MannWhitney U test; $p=0.09$; asBP: Systolic Blood Pressure; 'DBP: Diastolic Blood Pressure; 'PP: Pulse Pressure; dMAP: Mean Arterial Pressure; ${ }^{\mathrm{C}} \mathrm{cf}-\mathrm{PWV}$ : Carotid-femoral Pulse Wave Velocity; fAlx: Augmentation Index; gIMT: Intimamedia thickness.

Table 2: Central and peripheral arterial parameters.

\section{Determinants of central arterial parameters}

Multivariate regression models analysing factors independently correlated with central arterial parameters are summarized in table 3 .
Age $(\mathrm{p}<0.0001)$, MAP $(\mathrm{p}<0.0001)$ and diabetic status $(\mathrm{p}=0.021)$ were positively correlated with carotid-femoral PWV. Age $(\mathrm{p}<0.0001)$, gender $(\mathrm{p}<0.0001)$, MAP $(\mathrm{p}<0.0001)$, and CD4 T-cell count $(\mathrm{p}=0.012)$ were positively correlated with carotid AIx, whereas heart rate $(\mathrm{p}<0.0001)$ was negatively correlated. A positive and linear correlation between vitamin $\mathrm{D}$ and PPA $(\mathrm{n}=133, \mathrm{r}=0.18, \mathrm{p}=0.04)$ (Figure 1) persisted in the multiple regression analysis independently of the other cofactors as shown in Table 3. Gender $(\mathrm{p}<0.0001)$ and MAP $(\mathrm{p}=0.001)$ were negatively correlated with PPA, whereas vitamin D $(\mathrm{p}=0.042)$ and heart rate $(\mathrm{p}<0.0001)$ were positively correlated. Age was not independently associated with PPA in our study population.

\begin{tabular}{|c|c|c|c|c|c|}
\hline \multirow[t]{5}{*}{ PWV ${ }^{* a}$} & & coefficient & SE & partial $\mathbf{R}^{2}$ & $P$ value \\
\hline & Age & 0.006 & 0.001 & 0.090 & $<0.0001$ \\
\hline & $\begin{array}{l}\text { Mean arterial } \\
\text { pressure }^{*}\end{array}$ & 0.745 & 0.099 & 0.266 & $<0.0001$ \\
\hline & Diabetes & 0.139 & 0.060 & 0.033 & 0.021 \\
\hline & Adjusted $\mathrm{R}^{2}$ & & & 0.371 & \\
\hline \multirow[t]{7}{*}{$A \mid x^{b}$} & & coefficient & SE & partial $\mathbf{R}^{2}$ & $P$ value \\
\hline & Age & 0.487 & 0.121 & 0.099 & $<0.0001$ \\
\hline & $\begin{array}{l}\text { Mean arterial } \\
\text { pressure* }\end{array}$ & 63.941 & 9.289 & 0.244 & $<0.0001$ \\
\hline & Heart rate & -0.744 & 0.085 & 0.341 & $<0.0001$ \\
\hline & Gender & 18.913 & 2.644 & 0.258 & $<0.0001$ \\
\hline & Current $\mathrm{CD} 4$ count $^{*}$ & 15.559 & 6.133 & 0.042 & 0.012 \\
\hline & Adjusted $\mathrm{R}^{2}$ & & & 0.537 & \\
\hline \multirow[t]{7}{*}{ PPA $^{c}$} & & coefficient & SE & partial $\mathbf{R}^{2}$ & $P$ value \\
\hline & Age & -0.003 & 0.002 & 0.016 & 0.157 \\
\hline & $\begin{array}{l}\text { Mean arterial } \\
\text { pressure }\end{array}$ & -0.445 & 0.133 & 0.081 & 0.001 \\
\hline & Heart rate & 0.006 & 0.001 & 0.148 & $<0.0001$ \\
\hline & Gender & -0.196 & 0.041 & 0.153 & $<0.0001$ \\
\hline & $\begin{array}{l}\text { 25-hydroxyvitamin } \\
D^{*}\end{array}$ & 0.059 & 0.029 & 0.032 & 0.042 \\
\hline & Adjusted $\mathrm{R}^{2}$ & & & 0.283 & \\
\hline
\end{tabular}

"Log-transformed; aPWV: Pulse Wave Velocity; ' ${ }^{\text {Aix: }}$ Augmentation Index; 'PPA: Pulse Pressure Amplification; SE: Standard Error. Variables in the selection models were age, mean arterial pressure, heart rate, gender, diabetes, smoking status, waist circumference, 25-hydroxyvitamin D level, protease inhibitor treatment, nadir CD4 count, and current CD4 count.

Table 3: Determinants of aortic PWV, carotid AIx, and PPA.

Multivariate regression models analysing factors independently correlated with carotid IMT and carotid plaque are summarized in table 4. Age $(\mathrm{p}<0.0001)$, waist circumference $(\mathrm{p}<0.0001)$ and brachial $\mathrm{SBP}(\mathrm{p}=0.031)$ were positively correlated with carotid IMT.

Age $(\mathrm{p}=0.013)$ and active or past smoking $(\mathrm{p}=0.027)$ were positively correlated with carotid plaques. 
Citation: Yannoutsos A, Agnoletti D, Peroz-Froz J, Camille Ly, Lelong H, et al. (2014) Structural and Functional Arterial Parameters, Immunovirological Control and Vitamin D in HIV-Infected Patients. J AIDS Clin Res 5: 375. doi:10.4172/2155-6113.1000375

Page 5 of 9

\section{Discussion}

Our study population included middle-aged patients with controlled HIV infection in a large number of participants. Nearly all patients were virologically suppressed at the time of enrollment. Aortic PWV was slightly but unsignificantly higher than the reference values found in the general population according to age and BP. To the best of our knowledge, it is the first time that better immune status, as reflected by the CD4 T-cell count, was independently associated with a transit time-dependent marker of intensity of wave reflections. Plasma vitamin D and PPA were positively and independently correlated, suggesting that vitamin $\mathrm{D}$ deficiency may be associated with altered central hemodynamic parameters in well controlled HIV-infected patients.

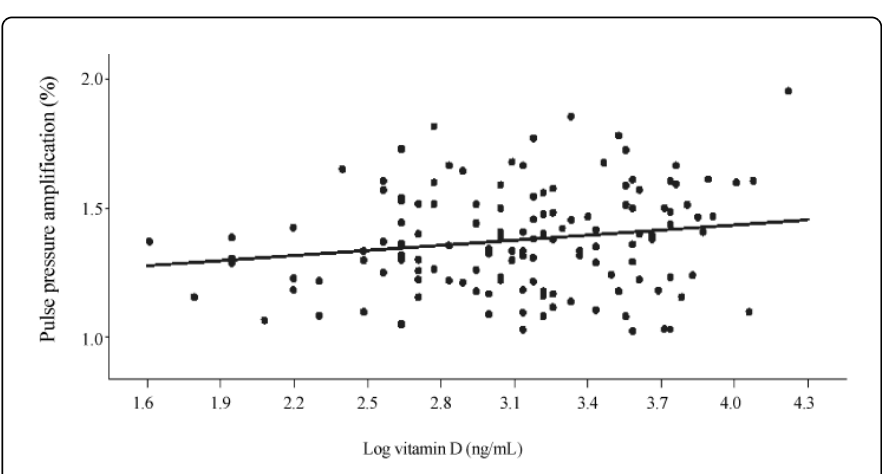

Figure 1: Correlation between 25-hydroxyvitamin D and pulse pressure amplification.

\begin{tabular}{|c|c|c|c|c|c|}
\hline \multirow[t]{5}{*}{ IMT'a } & & Coefficient & SE & partial $\mathbf{R}^{2}$ & $P$ value \\
\hline & Age & 0.006 & 0.002 & 0.076 & $<0.0001$ \\
\hline & $\begin{array}{l}\text { Waist } \\
\text { circumference }\end{array}$ & 0.005 & 0.001 & 0.079 & $<0.0001$ \\
\hline & Brachial SBPb & 0.002 & 0.001 & 0.028 & 0.031 \\
\hline & Adjusted $\mathrm{R}^{2}$ & & & 0.206 & \\
\hline \multirow[t]{3}{*}{ PLAQUE } & & OR & \multicolumn{2}{|c|}{$95 \% \mathrm{CL}$} & $P$ value \\
\hline & Age & 1.091 & 1.018 & 1.168 & 0.013 \\
\hline & $\begin{array}{l}\text { Active or past } \\
\text { smoking }\end{array}$ & 2.245 & 1.096 & 4.598 & 0.027 \\
\hline
\end{tabular}

aIMT: Intima-media Thickness; SBPb: Systolic Blood Pressure. Variables in the selection models were age, gender, brachial SBP, brachial DBP, diabetes, smoking status, waist circumference, 25-hydroxyvitamin D level, protease inhibitor treatment, nadir CD4 count, current CD4 count

Table 4: Determinants of carotid IMT and carotid plaque, respectively by multivariate linear and logistic regression.

\section{Central arterial parameters and HIV infection}

Aortic PWV: In our study population, mean \pm SD age was $49 \pm 9$ years and the median (IQR) for carotid-femoral PWV was 8.3(7.5-9.5) $\mathrm{m} / \mathrm{s}$, which was slightly, but not significantly higher than the theoretical value which was $8.0(7.4-9.1) \mathrm{m} / \mathrm{s}$ according to the same age category, on the basis of MAP. Gold standard of normal and reference values for carotid-femoral PWV have been established previously based on an extensive data set obtained from 13 centers distributed across Europe, taking into account different methodological approaches for the determination of PWV [29]. Advancing age and distending pressure appear to be the most important determinants of altered buffering function resulting from aortic wall stiffening [33]. Aortic PWV reference values represent reliable estimates according to age and BP, allowing comparison with carotid-femoral PWV in our study population.

Consistent with our results, similar values of aortic PWV in HIVinfected patients in the HAART era compared to uninfected individuals were recently described [18,34]. Age, MAP and diabetic status were independent factors associated with increased aortic PWV in our study, with a strong correlation with age and MAP, findings highly consistent with the literature $[33,35]$. Contribution of other CV risk factors was nonsignificant and, interestingly, the presence of the metabolic syndrome, found in more than half of patients, did not enter the multiple regression analysis. In diabetic patients, longer past exposure to metabolic abnormalities may have a more marked impact on arterial stiffness.

A relationship between increased aortic stiffness and PI treatment in HIV-infected patients has been described in many observational studies, independently of conventional CV risk factors [9,20,36,37]. In our study population, neither HIV-related parameters or PI treatment entered the explicative model of aortic PWV, consistent with recently published results [32]. It should be noted that there is some controversy on whether PIs or other antiretroviral classes are indeed associated with CV risk [38]. Furthermore, interruption of ART has been associated with an increased risk of death and CV diseases comparatively to continuous treatment [39], suggesting that immunological benefits of drugs exceed the CV risk of metabolic side effects. In addition, we studied a group of middle-aged patients with extremely good virological control in a large number of participants and significant CV prevention implementation (only 13\% were active smokers, $20 \%$ and $22 \%$ were on a statin and anti-hypertensive drugs, respectively). This may contribute to explain the discrepancy with previous studies showing higher PWV values in HIV-positive than in HIV-negative persons $[9,36,37]$. As age (in association with MAP) is the major determinant of aortic stiffness, the longitudinal follow-up of our study population would provide further evidence about early vascular aging and its determinants in HIV-infected patients with viral suppression.

Carotid AIx: CD4 T-cell count was the only independent HIVrelated factor modulating carotid AIx, with a positive relation: increased carotid AIx was significantly associated with higher CD4 Tcell counts. The other independent factors modulating positively carotid AIx were age, MAP and female gender, consistent with the literature $[34,40]$. As expected, heart rate was negatively correlated with AIx [16].

The positive correlation found with current CD4 T-cell count seems in contrast with previous studies linking increased arterial stiffness with HIV infection. Little evidence and inconsistent results exist about the relationship between immunological parameters and arterial wave reflections among heterogeneous study populations. Ho et al. found, in a cross-sectional study of 134 middle-aged HIV-infected men, that increased aortic stiffness and wave reflections were independently related in multivariate models to a nadir CD4 T-cell count $<350 / \mathrm{mm}^{3}$ at HAART initiation [19]. In a cohort of 32 young HIV-infected 
Citation: Yannoutsos A, Agnoletti D, Peroz-Froz J, Camille Ly, Lelong H, et al. (2014) Structural and Functional Arterial Parameters, Immunovirological Control and Vitamin D in HIV-Infected Patients. J AIDS Clin Res 5: 375. doi:10.4172/2155-6113.1000375

Page 6 of 9

patients treated with PIs and $32 \mathrm{HIV}$-uninfected subjects, Schillaci et al. [20] found that HIV infection was independently associated with increased aortic PWV and central AIx in multiple regression models. The authors suggested that immunodeficiency may account for vascular damage with earlier return of reflected waves at central level. However, the number of studied subjects was small. In contrast, Lazar et al. reported no association between HIV infection and increased arterial wave reflections in a homogeneous group of 276 HIV-infected and $67 \mathrm{HIV}$-uninfected Rwandan young women. In addition, current CD4 T-cell count among HIV-infected women did not correlate with central AIx or central PP [21].

In the present study, we found a strong positive association between carotid AIx and current CD4 T-cell count which persisted in multiple regression analysis independently of age, MAP, gender and heart rate. From a physiopathological viewpoint, AIx is a dependent measure of reflected wave transit time which may be related either to the compliance of the aorta or to increased heart rate. Increased heart rate is associated with a reduction in the time required for the backward pressure wave to return toward the heart without any change in aortic stiffness. Furthermore, central AIx may be an unreliable indicator of aortic stiffness in middle-aged or even older patients, relative wave reflections remaining unchanged or even reduced in elderly individuals whereas aortic stiffness is increased [41]. This positive and independent correlation between CD4 T-cell count and a transit timedependent marker of intensity of wave reflections does not imply a causal relationship between higher CD4 T-cell counts and altered wave reflections. In HIV-infected patients without overt increased aortic stiffness, this positive correlation, which persisted independently of heart rate, might suggest that patients with higher CD4 T-cell count have simply a more distensible aorta. Indeed, impedance mismatch at the junction between a normally compliant aorta and carotid artery represents a protective mechanism which facilitates pressure wave reflection and limits the transmission of excessive pulsatile energy into the microcirculation. Of course, this interpretation must be confirmed in longitudinal follow-up with a matched control group. Finally, differences in clinical characteristics between our study population and the previously published cohorts have to be considered: we studied a group of middle-aged HIV-infected men and women, chronically treated and virologically suppressed at the time of enrollment, and without overt increased aortic stiffness.

\section{Carotid IMT and carotid plaque}

Carotid plaque is a marker of the presence and extent of coronary artery disease and an independent predictor of CV events and mortality. Prevalence of ultrasonographic carotid plaque was $11 \%$ in our study population of middle-aged patients. A similar prevalence of carotid atherosclerosis has been observed in the general population [42] although a direct comparison with our results is difficult, because of the absence of an age-matched control group. Consistent with a recent meta-analysis of observational studies [43], we found that parameters of HIV infection or PI exposure were not independently associated with carotid plaque. Age and smoking have emerged as leading risk factors of carotid atherosclerosis in the literature [42,44]. As expected, age and smoking status were independently and positively correlated with the prevalence of carotid plaque in our study population.

A number of studies in HIV-infected patients used carotid IMT as a screening tool for risk assessment but this marker of early vascular aging may fail to identify patients at increased CV risk [11,12]. Carotid
IMT represents a structural quantitative analysis but does not account for qualitative components. The IMT reflects both intima damages (related to the atherosclerotic process) and media damages related to an adaptive process associated with age and distending pressure [45]. As expected, age and BP were independently associated with carotid IMT. No HIV-related parameters or PI treatment were independently associated with carotid IMT in our study population. We found that waist circumference, which is widely applied to estimate visceral obesity, was positively and independently associated with carotid IMT in our study population. In accordance with the present results, previous studies in middle-aged HIV-infected patients have highlighted that exposure to PI therapy or HIV infection might not be associated with an increased carotid IMT [46,47]. Indeed, in young and middle-aged individuals, traditional risk factors may overshadow impact of HAART exposure and HIV-infection in determining premature vascular lesions.

\section{Pulse pressure amplification and plasma vitamin D}

In our study population, vitamin D insufficiency $(25 \mathrm{OHD}<30 \mathrm{ng} /$ $\mathrm{ml})$, and deficiency $(25 \mathrm{OHD}<20 \mathrm{ng} / \mathrm{ml})$ were prevalent. Plasma vitamin D level was positively associated with PPA in our study population, and persisted in multiple regression analysis independently of MAP, gender and heart rate. Age was not independently related to PPA, although age and female gender are considered the most important non-modifiable determinants of decreased PPA [16]. However, the independent value of age may be minimized in the present study: in our population, gender may represent a stronger predictor than age (since the age range was quite narrow), which could possibly attenuate the independent value of aging. As expected, heart rate was positively correlated with PPA [16].

Amplification of systolic and pulse pressures from central to peripheral sites depends on the timing and amplitude of the reflected waves and is thus closely related to aortic PWV and AIx. The decrease or disappearance of PPA has been shown to be predictive of an increased risk of all-cause and CV mortality in large community-based cohorts $[48,49]$. Although the strength of the correlation between vitamin D and PPA may appear weak in our study population, this positive relation did persist in the multiple regression analysis independently of the other cofactors. Our findings suggest that higher vitamin $\mathrm{D}$ levels may be associated with better central hemodynamic profile in HIV-infected patients, which is consistent with epidemiological evidence in healthy individuals. In fact, vitamin D levels have been inversely related to aortic stiffness, central AIx, central aortic systolic and diastolic BP, independently of age [50,51]. Mortality has been inversely and independently related to vitamin D deficiency in large prospective cohort studies [24,52]. In HIV-infected patients, vitamin $\mathrm{D}$ deficiency has been associated with endothelial dysfunction [53], and coronary lesions [54]. Recently, low vitamin D level has been shown to predict short term mortality in HIV-positive persons, in relation with exacerbated inflammation [55].

Mechanisms underlying the link between vitamin D status and CV disease may be related to central hemodynamic profile associated with aortic stiffness and/or wave reflections. However, these associations are derived from observational and cross-sectional studies and do not necessarily imply a causal relationship. Nevertheless, the growing body of observational data linking vitamin D insufficiency with the risk of mortality and consistent findings of high rates of low vitamin D levels in HIV-infected patients warrant further interventional studies to 
Citation: Yannoutsos A, Agnoletti D, Peroz-Froz J, Camille Ly, Lelong H, et al. (2014) Structural and Functional Arterial Parameters, Immunovirological Control and Vitamin D in HIV-Infected Patients. J AIDS Clin Res 5: 375. doi:10.4172/2155-6113.1000375

Page 7 of 9

investigate the relationship between vitamin $\mathrm{D}$, arterial parameters and CV health.

Our study has limitations common to cross-sectional design, especially in establishing cause-effect relationships between central hemodynamics, immunological parameters and vitamin D status. As our population was made mainly of well controlled infected patients, we could not investigate relationship between central hemodynamic parameters and overt viral replication, poorer immune status or poorer immune restoration. Immune restoration was fairly good in this population with a median of current CD4 T-cell count approaching $500 / \mathrm{mm}^{3}$ and with $94 \%$ of patients having a CD4 T-cell count above $200 / \mathrm{mm}^{3}$. Virological control is demonstrated by the fact that $90 \%$ of patients had a plasma viral load below the technique's detection limit, $4 \%$ had a viral load that was detectable below 400 RNA copies/ml (400 copies being the threshold for defining virological failure) and only $6 \%$ had a viral load above 400 copies $/ \mathrm{ml}$. The variable "viral load" showed a very skewed distribution. Thus, we could not incorporate this variable in the statistical analysis because of the small number of patients with a viral load of $400 \mathrm{copies} / \mathrm{ml}$ or more.

The relatively small size of our study population may have limited the strength of the correlations between HIV-related parameters, vitamin D status and central hemodynamics. Finally, the lack of HIVnegative control group may weaken some of our conclusions on the impact of immune status on arterial parameters. However, we believe that European reference values established for PWV in an extremely large population represent an important step towards the definition of normal and reference values, to which our population can be compared. Mattace-Raso et al. noted that diabetic subjects and subjects treated for hypertension and dyslipidaemia had significantly elevated PWV values, compared with untreated patients, even after correction for age and MAP and this is why the authors decided not to include these patients [29]. In our study population, 5\% of patients were diabetics and $20 \%$ and $22 \%$ were on statin and anti-hypertensive drugs, respectively. Statistical analysis comparing measured values and calculated theoretical values for aortic PWV has included all patients of our study population, which may strengthen our results. In the absence of reference and widely used values for PPA and carotid AIx, comparisons between HIV-infected and uninfected populations could not be undertaken and only determinants of these vascular parameters could be assessed in our study population.

In contrast to previous studies, our group of well-controlled HIVinfected patients did not show overtly increased aortic stiffness, when compared to the theoretical values. To the best of our knowledge, it is the first time that better immune status was associated with a transit time-dependent marker of intensity of wave reflections, in relation with the fact that patients under treatment with higher CD4 T-cell count may have unaltered buffering function. The positive correlation between vitamin $\mathrm{D}$ and amplification of $\mathrm{PP}$ suggests a possible beneficial impact of adequate vitamin $\mathrm{D}$ level on central hemodynamic parameters. Amplification of PP, which is modulated by vascular properties and inversely related to large artery stiffness and increased wave reflections, may provide further information about the relationship between vitamin $\mathrm{D}$, arterial parameters and CV health in HIV-infected patients.

\section{Acknowledgements}

The authors thank Agnès Cros and Aline Maignan for data collection and monitoring. This study was performed with the help of the grant from the French Society of Hypertension.

\section{References}

1. Palella FJ, Delaney KM, Moorman AC, Loveless MO, Fuhrer J, et al. (1998) Declining morbidity and mortality among patients with advanced human immunodeficiency virus infection. HIV Outpatient Study Investigators. N Engl J Med 338: 853-860.

2. Lewden C, May T, Rosenthal E, Burty C, Bonnet F, et al. (2008) Changes in causes of death among adults infected by HIV between 2000 and 2005: The "Mortalité 2000 and 2005" surveys (ANRS EN19 and Mortavic). J Acquir Immune Defic Syndr 48: 590-598.

3. Lohse N, Hansen AB, Gerstoft J, Obel N (2007) Improved survival in HIV-infected persons: consequences and perspectives. J Antimicrob Chemother 60: 461-463.

4. Morlat P, Roussillon C, Henard S, Salmon D, Bonnet F, et al. (2014) Causes of death among HIV-infected patients in France in 2010 (national survey): trends since 2000. AIDS 28: 1181-1191.

5. Lang S, Mary-Krause M, Simon A, Partisani M, Gilquin J, et al. (2012) HIV replication and immune status are independent predictors of the risk of myocardial infarction in HIV-infected individuals. Clin Infect Dis 55: 600-607.

6. Lang S, Mary-Krause M, Cotte L, Gilquin J, Partisani M, et al. (2010) Impact of individual antiretroviral drugs on the risk of myocardial infarction in human immunodeficiency virus-infected patients: a casecontrol study nested within the French Hospital Database on HIV ANRS Cohort CO4. Arch Intern Med 170: 1228-1238.

7. Rodger AJ, Lodwick R, Schechter M, Deeks S, Amin J, et al. (2013) Mortality in well controlled HIV in the continuous antiretroviral therapy arms of the SMART and ESPRIT trials compared with the general population. AIDS 27: 973-979.

8. Friis-Møller N, Worm SW (2007) Can the risk of cardiovascular disease in HIV-infected patients be estimated from conventional risk prediction tools? Clin Infect Dis 45: 1082-1084.

9. Lekakis J, Ikonomidis I, Palios J, Tsiodras S, Karatzis E, et al. (2009) Association of highly active antiretroviral therapy with increased arterial stiffness in patients infected with human immunodeficiency virus. Am J Hypertens 22: 828-834.

10. Monsuez JJ, Charniot JC, Escaut L, Teicher E, Wyplosz B, et al. (2009) HIV-associated vascular diseases: structural and functional changes, clinical implications. Int J Cardiol 133: 293-306.

11. Den Ruijter HM, Peters SA, Anderson TJ, Britton AR, Dekker JM, et al. (2012) Common carotid intima-media thickness measurements in cardiovascular risk prediction: a meta-analysis. JAMA 308: 796-803.

12. Lorenz MW, Polak JF, Kavousi M, Mathiesen EB, Völzke H, et al. (2012) PROG-IMT Study Group. Carotid intima-media thickness progression to predict cardiovascular events in the general population (the PROG-IMT collaborative project): a meta-analysis of individual participant data. Lancet 379: 2053-2062.

13. Blacher J, Asmar R, Djane S, London GM, Safar ME (1999) Aortic pulse wave velocity as a marker of cardiovascular risk in hypertensive patients. Hypertension 33: 1111-1117.

14. Mattace-Raso FU, van der Cammen TJ, Hofman A, van Popele NM, Bos ML, et al. (2006) Arterial stiffness and risk of coronary heart disease and stroke: the Rotterdam Study. Circulation 113: 657-663.

15. Ben-Shlomo Y, Spears M, Boustred C, May M, Anderson SG, et al. (2014) Aortic pulse wave velocity improves cardiovascular event prediction: an individual participant meta-analysis of prospective observational data from 17,635 subjects. J Am Coll Cardiol 63: 636-646.

16. Avolio AP, Van Bortel LM, Boutouyrie P, Cockcroft JR, McEniery CM, et al. (2009) Role of pulse pressure amplification in arterial hypertension: experts' opinion and review of the data. Hypertension 54: 375-383. 
Citation: Yannoutsos A, Agnoletti D, Peroz-Froz J, Camille Ly, Lelong H, et al. (2014) Structural and Functional Arterial Parameters, Immunovirological Control and Vitamin D in HIV-Infected Patients. J AIDS Clin Res 5: 375. doi:10.4172/2155-6113.1000375

Page 8 of 9

17. Vlachopoulos C, Aznaouridis K, O'Rourke MF, Safar ME, Baou K, et al. (2010) Prediction of cardiovascular events and all-cause mortality with central haemodynamics: a systematic review and meta-analysis. Eur Heart J 31: 1865-1871.

18. Echeverría P, Bonjoch A, Moltó J, Jou A, Puig J, et al. (2014) Pulse wave velocity as index of arterial stiffness in HIV-infected patients compared with a healthy population. J Acquir Immune Defic Syndr 65: 50-56.

19. Ho JE, Deeks SG, Hecht FM, Xie Y, Schnell A, et al. (2010) Initiation of antiretroviral therapy at higher nadir CD4+ T-cell counts is associated with reduced arterial stiffness in HIV-infected individuals. AIDS 24: 1897-1905.

20. Schillaci G, De Socio GV, Pirro M, Savarese G, Mannarino MR, et al. (2005) Impact of treatment with protease inhibitors on aortic stiffness in adult patients with human immunodeficiency virus infection. Arterioscler Thromb Vasc Biol 25: 2381-2385.

21. Lazar JM, Wu X, Shi Q, Kagame A, Cohen M, et al. (2009) Arterial wave reflection in HIV-infected and HIV-uninfected Rwandan women. AIDS Res Hum Retroviruses 25: 877-882.

22. Dao CN, Patel P, Overton ET, Rhame F, Pals SL, et al. (2011) Low vitamin D among HIV-infected adults: prevalence of and risk factors for low vitamin D Levels in a cohort of HIV-infected adults and comparison to prevalence among adults in the US general population. Clin Infect Dis 52: 396-405.

23. Wang TJ, Pencina MJ, Booth SL, Jacques PF, Ingelsson E, et al. (2008) Vitamin D deficiency and risk of cardiovascular disease. Circulation 117: 503-511.

24. Dobnig H, Pilz S, Scharnagl H, Renner W, Seelhorst U, et al. (2008) Independent association of low serum 25-hydroxyvitamin $d$ and 1,25dihydroxyvitamin d levels with all-cause and cardiovascular mortality. Arch Intern Med 168: 1340-1349.

25. Viard JP, Souberbielle JC, Kirk O, Reekie J, Knysz B, et al. (2011) Vitamin $\mathrm{D}$ and clinical disease progression in HIV infection: results from the EuroSIDA study. AIDS 25: 1305-1315.

26. Wilkinson IB, Fuchs SA, Jansen IM, Spratt JC, Murray GD, et al. (1998) Reproducibility of pulse wave velocity and augmentation index measured by pulse wave analysis. J Hypertens 16: 2079-2084.

27. Lieber A, Millasseau S, Bourhis L, Blacher J, Protogerou A, et al. (2010) Aortic wave reflection in women and men. Am J Physiol Heart Circ Physiol 299: H236-242.

28. Laurent S, Cockcroft J, Van Bortel L, Boutouyrie P, Giannattasio C, et al. (2006) Expert consensus document on arterial stiffness: methodological issues and clinical applications. Eur Heart J 27: 2588-2605.

29. Mattace-Raso F, Hofman A, Verwoert GC, Wittemana JC, Wilkinson I, et al. (2010) Determinants of pulse wave velocity in healthy people and in the presence of cardiovascular risk factors: 'establishing normal and reference values'. Eur Heart J 31: 2338-2350.

30. Segers P, Rietzschel E, Heireman S, De Buyzere M, Gillebert T, et al. (2005) Carotid tonometry versus synthesized aorta pressure waves for the estimation of central systolic blood pressure and augmentation index. Am J Hypertens 18: 1168-1173.

31. McEniery CM, Yasmin, Hall IR, Qasem A, Wilkinson IB, et al. (2005) Normal vascular aging: differential effects on wave reflection and aortic pulse wave velocity: the Anglo-Cardiff Collaborative Trial (ACCT). J Am Coll Cardiol 46: 1753-1760.

32. Kelly R, Hayward C, Avolio A, O'Rourke M (1989) Noninvasive determination of age-related changes in the human arterial pulse. Circulation 80: 1652-1659.

33. Cecelja M, Chowienczyk P (2009) Dissociation of aortic pulse wave velocity with risk factors for cardiovascular disease other than hypertension: a systematic review. Hypertension 54: 1328-1336.

34. Monteiro P, Miranda-Filho DB, Bandeira F, Lacerda HR, Chaves H, et al. (2012) Is arterial stiffness in HIV-infected individuals associated with HIV-related factors? Braz J Med Biol Res 45: 818-826.

35. Kimoto E, Shoji T, Shinohara K, Inaba M, Okuno Y, et al. (2003) Preferential stiffening of central over peripheral arteries in type 2 diabetes. Diabetes 52: 448-452.
36. van Vonderen MG, Smulders YM, Stehouwer CD, Danner SA, Gundy CM, et al. (2009) Carotid intima-media thickness and arterial stiffness in HIV-infected patients: the role of HIV, antiretroviral therapy, and lipodystrophy. J Acquir Immune Defic Syndr 50: 153-161.

37. Schillaci G, De Socio GV, Pucci G, Mannarino MR, Helou J, et al. (2008) Aortic stiffness in untreated adult patients with human immunodeficiency virus infection. Hypertension 52: 308-313.

38. Durand M, Sheehy O, Baril JG, Lelorier J, Tremblay CL (2011) Association between HIV infection, antiretroviral therapy, and risk of acute myocardial infarction: a cohort and nested case-control study using Québec's public health insurance database. J Acquir Immune Defic Syndr 57: 245-253.

39. Strategies for Management of Antiretroviral Therapy (SMART) Study Group1, El-Sadr WM, Lundgren J, Neaton JD, Gordin F, et al. (2006) $\mathrm{CD} 4+$ count-guided interruption of antiretroviral treatment. $\mathrm{N}$ Engl J Med 355: 2283-2296.

40. Hayward CS, Kelly RP (1997) Gender-related differences in the central arterial pressure waveform. J Am Coll Cardiol 30: 1863-1871.

41. Vyas M, Izzo JL Jr, Lacourcière Y, Arnold JM, Dunlap ME, et al. (2007) Augmentation index and central aortic stiffness in middle-aged to elderly individuals. Am J Hypertens 20: 642-647.

42. Prati P, Vanuzzo D, Casaroli M, Di Chiara A, De Biasi F, et al. (1992) Prevalence and determinants of carotid atherosclerosis in a general population. Stroke 23: 1705-1711.

43. Hulten E, Mitchell J, Scally J, Gibbs B, Villines TC (2009) HIV positivity, protease inhibitor exposure and subclinical atherosclerosis: a systematic review and meta-analysis of observational studies. Heart 95: 1826-1835.

44. Dempsey RJ, Moore RW (1992) Amount of smoking independently predicts carotid artery atherosclerosis severity. Stroke 23: 693-696.

45. Roman MJ, Saba PS, Pini R, Spitzer M, Pickering TG, et al. (1992) Parallel cardiac and vascular adaptation in hypertension. Circulation 86: 1909-1918.

46. Currier JS, Kendall MA, Zackin R, Henry WK, Alston-Smith B, et al. (2005) Carotid artery intima-media thickness and HIV infection: traditional risk factors overshadow impact of protease inhibitor exposure. AIDS 19: 927-933.

47. Bongiovanni M, Casana M, Cicconi P, Pisacreta M, Codemo R, et al. (2008) Predictive factors of vascular intima media thickness in HIVpositive subjects. J Antimicrob Chemother 61: 195-199.

48. Benetos A, Safar M, Rudnichi A, Smulyan H, Richard JL, et al. (1997) Pulse pressure: a predictor of long-term cardiovascular mortality in a French male population. Hypertension 30: 1410-1415.

49. Benetos A, Thomas F, Joly L, Blacher J, Pannier B, et al. (2010) Pulse pressure amplification a mechanical biomarker of cardiovascular risk. J Am Coll Cardiol 55: 1032-1037.

50. Alvarez JA, Gower BA, Calhoun DA, Judd SE, Dong Y, et al. (2012) Serum 25-hydroxyvitamin D and Ethnic Differences in Arterial Stiffness and Endothelial Function. J Clin Med Res 4: 197-205.

51. Al Mheid I, Patel R, Murrow J, Morris A, Rahman A, et al. (2011) Vitamin D status is associated with arterial stiffness and vascular dysfunction in healthy humans. J Am Coll Cardiol 58: 186-192.

52. Melamed ML, Michos ED, Post W, Astor B (2008) 25-hydroxyvitamin D levels and the risk of mortality in the general population. Arch Intern Med 168: 1629-1637.

53. Shikuma CM, Seto T, Liang CY, Bennett K, DeGruttola V, et al. (2012) Vitamin D levels and markers of arterial dysfunction in HIV. AIDS Res Hum Retroviruses 28: 793-797.

54. Lai H, Gerstenblith G, Fishman EK, Brinker J, Kickler T, et al. (2012) Vitamin $\mathrm{D}$ deficiency is associated with silent coronary artery disease in cardiovascularly asymptomatic African Americans with HIV infection. Clin Infect Dis 54: 1747-1755.

55. Shepherd L, Souberbielle JC, Bastard JP, Fellahi S, Capeau J, et al. (2014) Prognostic value of vitamin D level for all-cause mortality, and association with inflammatory markers, in HIV-infected persons. J Infect Dis 210: 234-243. 
Citation: Yannoutsos A, Agnoletti D, Peroz-Froz J, Camille Ly, Lelong H, et al. (2014) Structural and Functional Arterial Parameters, Immunovirological Control and Vitamin D in HIV-Infected Patients. J AIDS Clin Res 5: 375. doi:10.4172/2155-6113.1000375 